Document downloaded from:

http://hdl.handle.net/10251/57706

This paper must be cited as:

Dolz Ruiz, V.; Novella Rosa, R.; García Martínez, A.; Sánchez Serrano, J. (2012). HD Diesel engine equipped with a bottoming Rankine cycle as a waste heat recovery system. Part 1: Study and analysis of the waste heat energy. Applied Thermal Engineering. 36:269-278. doi:10.1016/j.applthermaleng.2011.10.025.

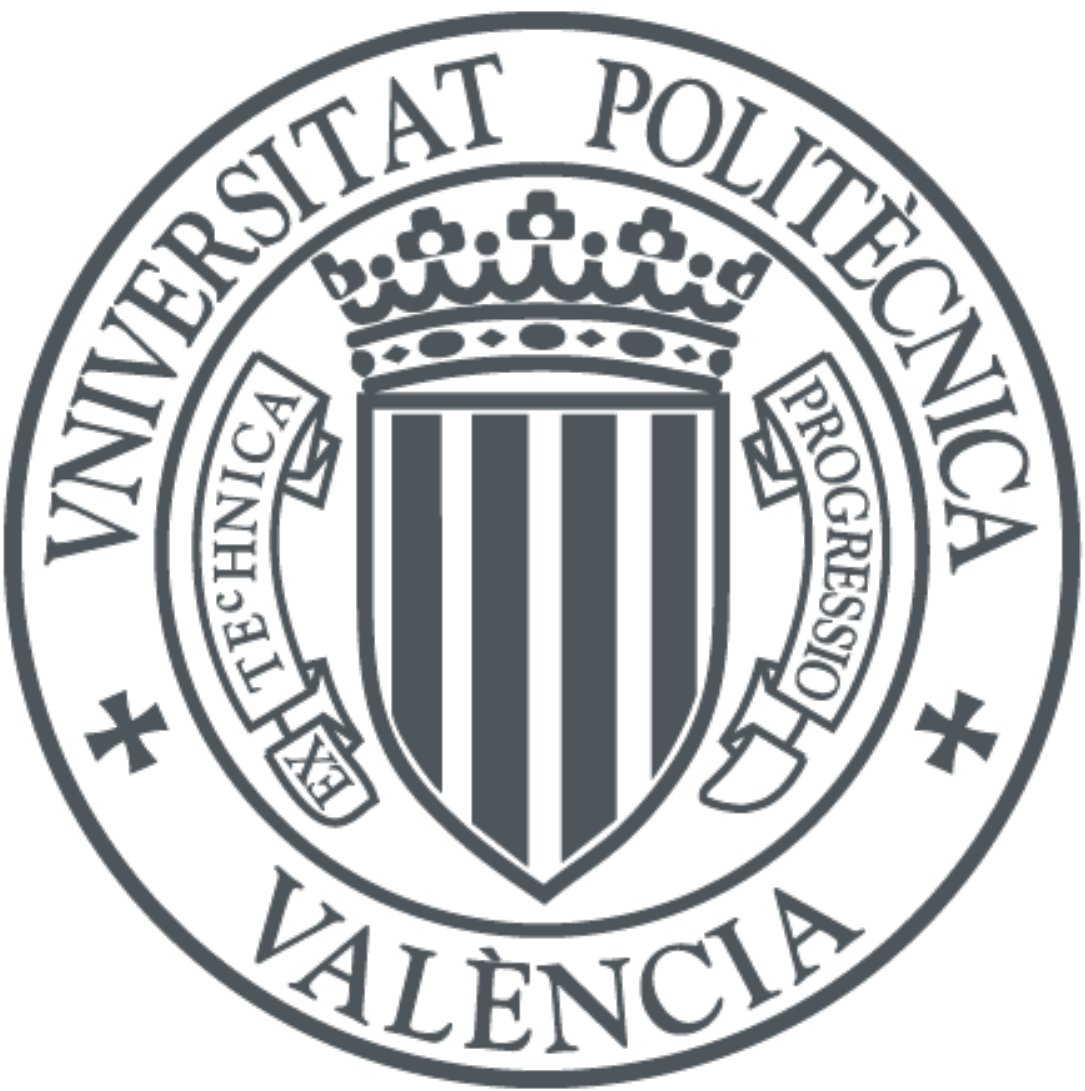

The final publication is available at

http://dx.doi.org/10.1016/j.applthermaleng.2011.10.025

Copyright Elsevier

Additional Information 


\title{
HD Diesel engine equipped with a bottoming Rankine cycle as a waste heat recovery system. Part 1: Study and Analysis of the Waste Heat Energy
}

\author{
Authors: V. Dolz, R. Novella, A. García, J. Sánchez
}

CMT - Motores Térmicos, Universitat Politècnica de València, Spain

\begin{abstract}
This paper describes the study of different bottoming Rankine cycles with water-steam and/or ORC configurations in classical and innovative setups such as a waste heat recovery system in a Heavy Duty Diesel (HDD) Engine. This work has been divided in two parts. This first part describes the model of the studied HDD engine and the available waste energy sources in this HDD Engine. The waste energy sources are studied from the standpoint of energy analysis to determine which are the most appropriate for their application in bottoming cycles attending to minimizing external irreversibilities. Finally, two configurations are chosen as the most appropriate, in a balance between external irreversibilities and technological complexity, and they have been analyzed to determine global efficiencies, power increments and necessary modifications to implement these cycles in the HDD engine. The second part of this article will analyze additional innovative setups in the HDD engine to fit this engine with ORC cycles.

Keywords:

Diesel engine, Engine efficiency, Pollutant emissions, Waste Heat Recovery, Bottoming Rankine Cycle, Organic Rankine Cycle.
\end{abstract}

\section{Nomenclature}

Acronyms

bsfc Brake Specific Fuel Consumption

EGR Exhaust Gas Recirculation

HDD Heavy Duty Diesel

ORC Organic Rankine Cycle
OpenWAM ${ }^{\mathrm{TM}}$ Open Wave Action Model

\author{
Symbols \\ $C_{p}$ specific heat ratio \\ $\eta$ efficiency
}




\section{Introduction}

The increasing fuel costs and diminishing petroleum supplies are forcing governments and industries to increase the power efficiency of engines. A cursory look at the internal combustion engine heat balance indicates that the input energy is divided into roughly three equal parts: energy converted to useful work, energy transferred to coolant and energy lost with the exhaust gases. There are several technologies for recovering this energy on a Heavy Duty Diesel (HDD) engine, whereas the dominating ones are:

- Mechanical turbocompounding. The Diesel engine is equipped with an additional power turbine [1], [2]. The power turbine is placed in the exhaust line and is mechanically coupled to the engine crankshaft via a gear train.

- Electrical turbocompounding. The system consists of an electric motor/generator coupled by means of a turbocharger [3], [4]. The generator extracts surplus power from the turbine, and the electricity produced is used to run a motor assembled/fitted to the engine crankshaft.

- Thermoelectric materials. The exhaust pipe contains a block with thermoelectric materials that generates a direct current, thus providing for at least some of the electric power requirements [5], [6].

- Rankine cycle. The system is based on the steam generation in a secondary circuit using the exhaust gas thermal energy to produce additional power by means of a steam expander. A special case of lowtemperature energy generation systems is the use of certain organic fluids instead of water in so-called Organic Rankine Cycle (ORC). This technique has the advantage compared with turbocompounding that does not have so an important impact on the engine pumping losses and with respect to thermoelectric materials that provides higher efficiency in the use of the residual thermal energy sources [1].

ORC is considered a way of converting different kinds of low temperature energies such as solar, geothermal, biomass and thermal energy of exhaust gases into electrical energy [7]. Several studies have examined Rankine cycles for exhaust gas heat recovery in vehicle applications [8], [9]. For instance, Thermo Electron Corporation tested a Diesel-Organic Rankine compound engine on Class 8 trucks [10]. The application in a specific vehicle requires a redesigned system to fit all system components [11]. The additional vehicle mass and system cost need to be determined to show its economic feasibility.

This paper presents a study on different bottoming Rankine cycle configurations for application in Diesel engines. The second part of this article analyzes new and more complex configurations to improve the global efficiency of the engine.

The objective of this first part of the paper is to evaluate the different theoretical bottoming cycle configurations applied as a waste heat recovery system. The amount of heat dissipated by the cooling system of an installed engine represents a heat source in a bottoming cycle. The 2 stage HDD engine used on this study is described in the experimental setup section. The engine is tested in order to validate a model that reproduces real working conditions. This model is used to calculate the waste heat sources. The model will be also used to perform further studies with different combinations of turbocharger and bottoming cycle system in the second part of the paper. In the study of the engine energy, all possible 
residual heat sources are analyzed separately considering their potential use in the different cycle configurations. This aspect is the main uniqueness of the work. To consider all possible sources of engine heat involves a highly complex work due to the variety of types of these sources. The adjustment of the heat exchange between these sources and the Rankine cycle vaporizer implies many restrictions that must be considered thus adding difficulty to the study. However, and due to the complexity of the final solution, the analysis of how all these heat sources can be used represents a study of possible maximum energy recovering (minimum external irreversibilities), which is the objective of this paper.

Finally, two basic engine configurations with bottoming cycles are compared to analyze the global efficiency increase of the engine.

\section{Experimental Setup and IC engine model}

The engine studied in this article is a 12 litre two-stage HDD engine [12]. Figure 1 shows the scheme of the engine. The selection of a two-stage engine for this work has been done in order to keep maximum dynamic capabilities of the resulting configuration once coupled with the bottoming cycle system; transients of this engine, without a bottoming cycle, have been experimentally analyzed in [12].

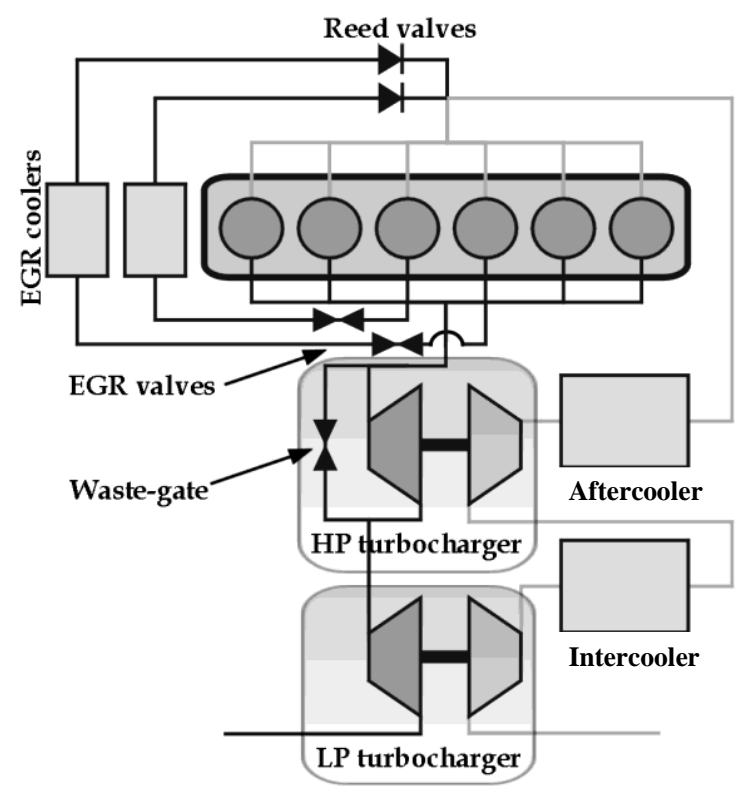

Figure 1. Reference configuration engine scheme

The engine model has been fitted using experimental data at full load conditions with different engine speeds. Some of these steady points are given in Table 1.

Table 1. Objective values for steady tests.

\begin{tabular}{|c|c|c|c|}
\hline Speed (rpm) & 1200 & 1500 & 1800 \\
\hline Max. Torque (Nm) & 2000 & 1950 & 1650 \\
\hline Max Power $(\mathrm{kW})$ & 251 & 306 & 311 \\
\hline $\mathrm{A} / \mathrm{F}$ & 20 & 21 & 23 \\
\hline EGR rate $(\%)$ & 29 & 30 & 30 \\
\hline
\end{tabular}


The steady point used in the present study is $1800 \mathrm{rpm}$ with full load conditions. The main reason for this selection is that this point has the highest available residual thermal sources. Consequently, it is considered the ideal point to assess the maximum usable energy in the engine.

The 1D gas-dynamics code used to model the engine is developed at "CMT-Motores Térmicos" and called OpenWAM ${ }^{\mathrm{TM}}$ [13], [14]. The model calculates the engine behaviour solving the unsteady equations of mass, momentum and energy conservation by means of finite differences scheme [15] in the ducts and a filling and emptying model in the cylinders [16], [17]. The resolution scheme used in this model is a two step Lax\&Wendroff scheme. The heat transfer model is developed from [18], [19] and fully described in [20]. The friction model is described in [14].

In addition, OpenWAM ${ }^{\mathrm{TM}}$ is able to reproduce the turbocharger performance based on the measured characteristics of the turbocharger. It is also capable of extrapolating operating conditions that differ from those included in the turbine maps, since the engines usually work within these points [21], [22].

The heat exchangers model is equivalent to that of two chambers and a pipe bundle in-between [23], [24] where the air is cooled by a coolant fluid.

A 5\% minimum error range in all parameters has been used to fit the engine model to the measured data in the investigated operating points.

\section{Study of the engine waste energy sources}

The selected engine steady point has been modelled with OpenWAM ${ }^{\mathrm{TM}}$ to study the possible waste heat sources in the engine. Afterwards, in order to analyze these waste heat sources, their fluid mass flows, temperatures, specific heats, and powers obtained by this model have been selected as input variables in the study of the engine waste energy sources. The main waste heat sources are:

- The exhaust gas heat energy.

- The EGR cooler.

- The intercooler, where the Low Pressure compressor outlet air is cooled.

- The aftercooler, where the High Pressure compressor outlet air is cooled also.

- Engine block cooling water.

Figure 2 shows the engine energy flows from the combustion of fuel to the dissipation of the waste heat sources to the atmosphere at $40^{\circ} \mathrm{C}$. Table 2 details the values of mass flow, temperature, specific heat and power in these sources. 


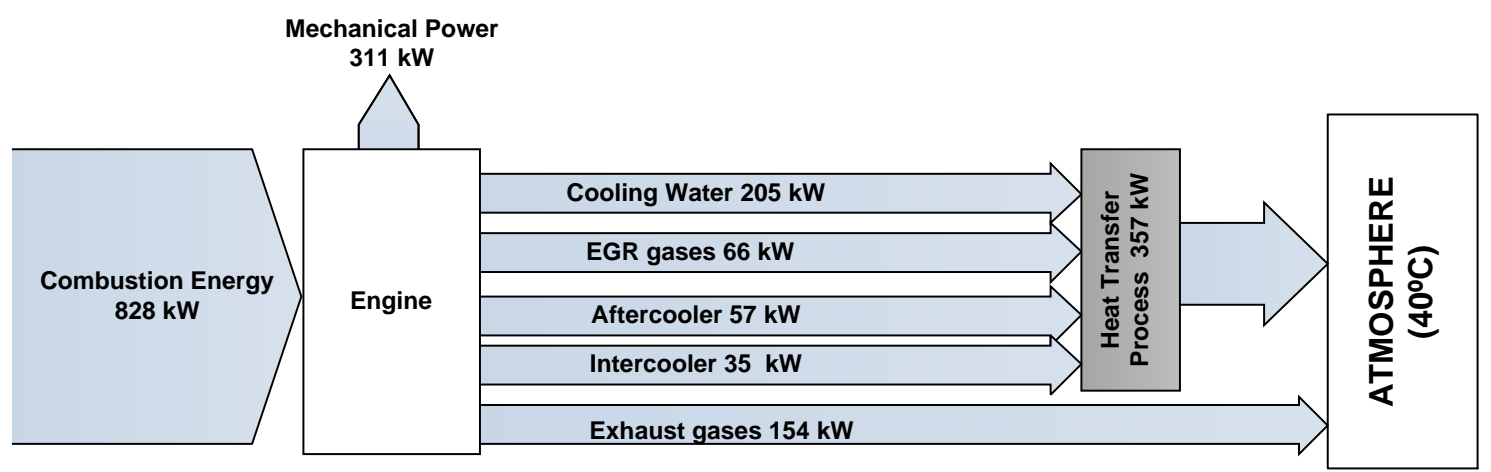

Figure 2. Energy scheme reference engine configuration.

Table 2. Residual heat sources properties

\begin{tabular}{cccccc}
\hline & \multicolumn{2}{c}{ Properties } & & & \\
\cline { 2 - 5 } & $\begin{array}{c}\text { Mass } \\
\text { flow } \\
(\mathrm{kg} / \mathrm{s})\end{array}$ & $\begin{array}{c}\text { Inlet } \\
\text { temperature } \\
\left({ }^{\circ} \mathrm{C}\right)\end{array}$ & $\begin{array}{c}\text { Outlet } \\
\text { temperature } \\
\left({ }^{\circ} \mathrm{C}\right)\end{array}$ & $\begin{array}{c}\mathrm{Cp} \\
(\mathrm{kJ} / \mathrm{kg} \mathrm{K})\end{array}$ & $\begin{array}{c}\text { Available } \\
\text { heat }(\mathrm{kW})\end{array}$ \\
\cline { 2 - 6 } Intercooler & 0.44 & 127 & 53 & 1.0 & 35 \\
Aftercooler & 0.44 & 172 & 49 & 1.0 & 57 \\
Exhaust gas & 0.45 & 330 & 40 & 1.1 & 154 \\
EGR cooler & 0.20 & 509 & 222 & 1.1 & 66 \\
Cooling Water & 9.80 & 85 & 80 & 4.1 & 205 \\
\hline
\end{tabular}

The main difficulty when using these energy sources in Rankine cycles is their low temperature. Rankine cycle efficiency depends on the heat source temperature value: the higher the source temperature, the better the efficiency of the Rankine cycle. Exergy studies of Diesel engines analyze this phenomenon; however, the present work does not cover this topic as they have already been published in previous works [25], [26], [27].

It can be expected that the waste heat energy from the lower temperature heat sources like refrigeration water, intercooler and aftercooler will be difficult to use in Rankine cycles. These waste heat sources represent half of the analyzed total waste energy. See Table 2. This will be discussed later on.

The following procedure has been used for analyzing engine energies and calculating theoretical Rankine cycles: First, the engine steady point has been modelled with OpenWAM ${ }^{\mathrm{TM}}$ to estimate possible waste heat sources. Second, the calculated available heat energies have been used in theoretical Rankine cycles, calculated with different fluids, where efficiencies, temperatures and powers have been estimated.

\section{Configuration with all waste heat sources. A single cycle.}

The performance of a bottoming Rankine cycle can be evaluated under diverse working conditions for the pre-selected working fluids (R-245fa, FC72, FC87, HFE7000, HFE7100, R-236fa, RC-318 and water). This pre-selection was performed by means a study similar to studies that can be found in the literature on 
selection of working fluid for Rankine cycles [28]. The analysis assumes the following: steady state conditions, no pressure drop in the vaporizer and condenser, and isentropic efficiencies for the expansion machine and pump of $100 \%$. Regarding the implementation of these configurations in the industry applications, an appropriated expander machine must be selected to obtain an acceptable efficiency and to consider the most important internal irreversibilities of these cycles. For this objective, the Japiske Turbine Chart [29] or Barber-Nichols Turbine Chart [30] can be utilized to approximate the most effective expander machine.

A parametric-iterative method has been employed for choosing the optimum working fluid and to obtain the maximum working fluid mass flow for each investigated vaporizer and superheater temperatures. Aiming to recover all of the available waste heat sources, the following criteria have been considered for the selection of the bottoming cycle working fluid:

- Pressure ratio in the expansion machine must be lower than 25 to achieve an efficient expansion process.

- The studied cycles must keep a minimum temperature difference between the working fluid and the engine heat sources to guarantee minimum irreversibilities in the heat transfer process. This difference is usually fixed to $10^{\circ} \mathrm{C}$ [31]. This is called Pinch-Point and it can be presented along with the fluid evaporation process. This point is usually denoted as "PP" as shown in Figure 3.

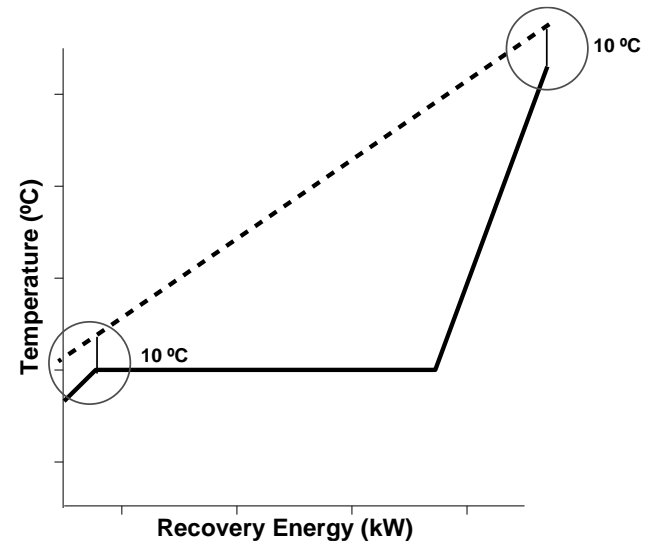

Figure 3. Schematic representation of waste heat temperature and working fluid temperature for a typical heat recovery system

Figure 4 shows the results (Output Power and Cycle Efficiency) of the working fluid parametric study. This figure shows only the results obtained for R245fa fluid and water since the other studied organic fluids provide similar results to those of R245fa. Since the energy used as a heat source in this case is typically wasted, the efficiency of the Rankine cycle is a secondary criterion. Thus, the main goal of the study is to maximize the power output. 

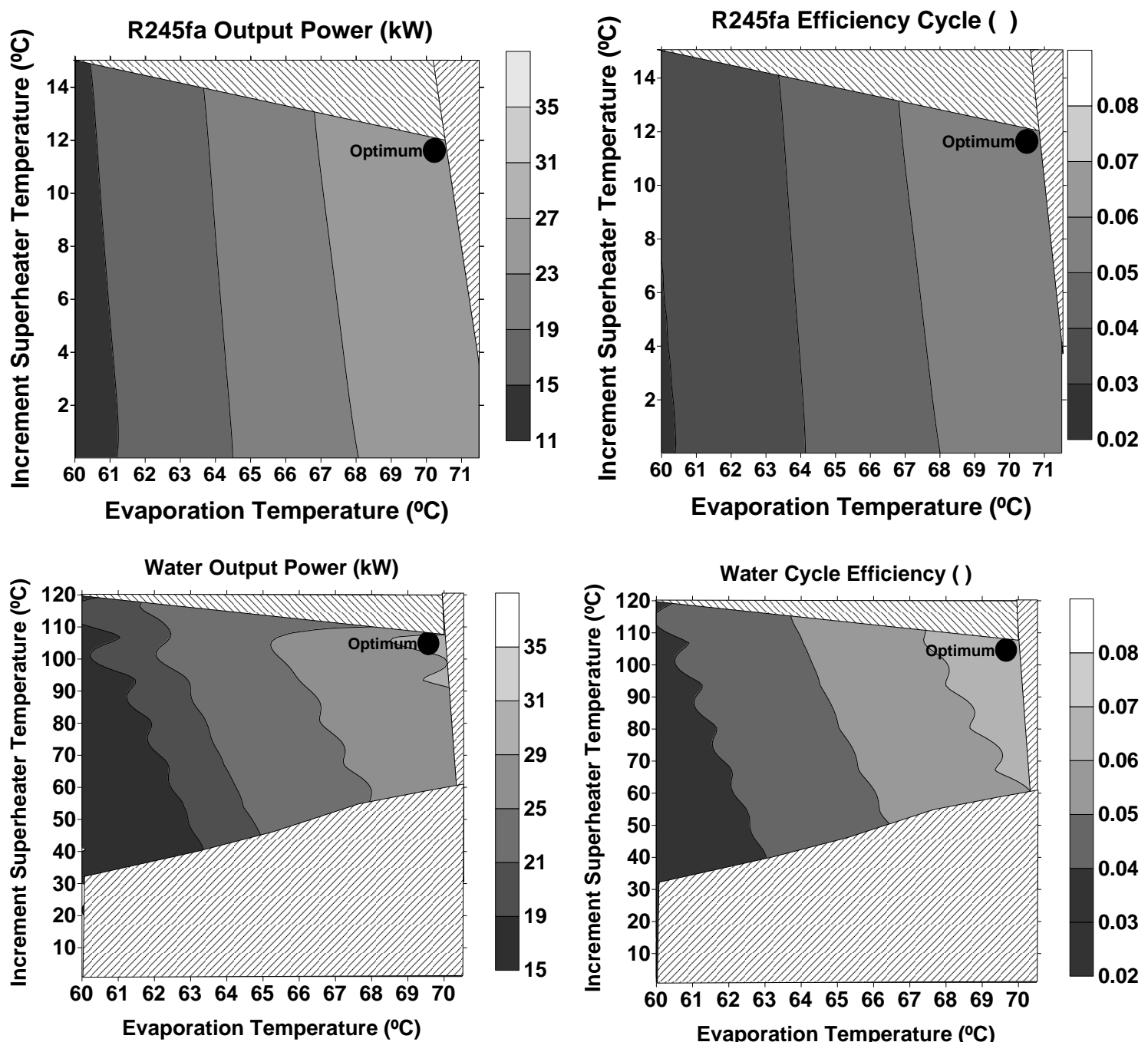

Figure 4. Plots of Output Power and Cycle Efficiency varying evaporator and superheater temperature (condensation temperature $50^{\circ} \mathrm{C}$ ).

The striped area on the right of the plot illustrates the working points that do not fulfil the Pinch Point restriction. In addition, the top striped area shows the zone where the mass flow necessary to maintain the cycle is so low that it does not allow a complete energy recovery for each of the considered heat sources. Finally, the bottom striped area corresponds to the Rankine cycles in which the expansion process crosses below the saturated steam curve (this area is only represented in the case of water because it has a saturated vapour curve with a negative slope).

Table 3. Cycle factor of optimum point for each working fluid considered

\begin{tabular}{cccccc}
\hline Working Fluid & $\begin{array}{c}\text { Mass } \\
\text { flow } \\
(\mathrm{kg} / \mathrm{s})\end{array}$ & $\begin{array}{c}\text { Vaporizer } \\
\text { Temperature } \\
\left({ }^{\circ} \mathrm{C}\right)\end{array}$ & $\begin{array}{c}\text { SuperHeater } \\
\text { Temperature } \\
\left({ }^{\circ} \mathrm{C}\right)\end{array}$ & $\begin{array}{c}\text { Work } \\
\text { Output } \\
(\mathrm{kW})\end{array}$ & $\begin{array}{c}\text { Cycle } \\
\text { Efficiency } \\
(\%)\end{array}$ \\
\hline R245fa & 2.4 & 71.0 & 80 & 27 & 6 \\
FC 72 & 5.0 & 71.0 & 75 & 27 & 6 \\
FC 87 & 5.0 & 70.0 & 82 & 26 & 6 \\
HFE7000 & 3.3 & 70.0 & 85 & 27 & 6 \\
HFE7100 & 3.7 & 70.0 & 85 & 27 & 6
\end{tabular}




\begin{tabular}{cccccc} 
R236fa & 3.3 & 71.5 & 83 & 27 & 6 \\
RC318 & 7.7 & 70.5 & 84 & 27 & 6 \\
Water & 0.2 & 70.0 & 177 & 31 & 7 \\
\hline
\end{tabular}

Table 3 shows the optimum points for each studied working fluid. A similar work output (around $27 \mathrm{~kW}$ ) and cycle efficiency (around 6\%) are obtained at similar working conditions for almost all investigated organic fluids. Therefore, the R245fa was selected as the working fluid in ORC with low temperature heat sources, due to its reasonable cycle output work and mild condensation pressure at $50^{\circ} \mathrm{C}$ [32].

This study becomes an unusual study. Generally, in conventional ORC studies, the researcher seeks a single heat source with a certain temperature and mass flow to analyze the best Rankine cycle, in order to maximize the obtained power. But in this study, from different heat sources selected previously (Table 2), which correspond to the wasted energy sources of the IC engine, the main objective is to find the Rankine cycle that best fits to these sources. Considering that some of these sources have the input and output temperatures fixed. This parametric study was made with a cycle which has a condensing temperature of $40^{\circ} \mathrm{C}$. If $70^{\circ} \mathrm{C}$ is considered as the evaporating temperature and the water is superheated to temperatures around $170^{\circ} \mathrm{C}$ (Figure 4), the water provides better results than the R245fa. This result is because the $\mathrm{R} 245 \mathrm{fa}$ in these conditions can not be superheated above $82^{\circ} \mathrm{C}$. The reason is the different pinch point restrictions that exist in the heat exchange between the different waste heat sources. Sometimes, these restrictions do not allow the energy recovering from all heat sources considered in the study (striped zones on top of the graphs in Figure 4). These considered sources have been included in Figure 5 (Top graphs) and they are very different i.e.: The thermal source with higher temperature is the EGR gases, which is cooled from $509^{\circ} \mathrm{C}$ to $222^{\circ} \mathrm{C}$, and the thermal source with lower temperature is the cooling water, which is typically cooled in the car radiator from $85^{\circ} \mathrm{C}$ to $80^{\circ} \mathrm{C}$, although this source gives more power $(205 \mathrm{~kW})$, due to high water flow and its specific heat. Due to these peculiarities of the considered heat sources, the optimal working fluid obtained does not correspond to an organic fluid, as initially could be expected.

However, due to the low temperature difference between the vaporizer and condenser, imposed by the initial restrictions, the achieved work output is not significant compared to the total waste heat given in Table 2. Figure 4 shows how the cycle using R245fa has better efficiency and output power than water in the low evaporation temperature zone. On the contrary, using water as a working fluid permits complete energy recovery at higher superheater temperature and also gives higher efficiency and power output. The main drawback is the low evaporation and condensation pressures when the water cycle operates with a temperature lower than $100^{\circ} \mathrm{C}$. 


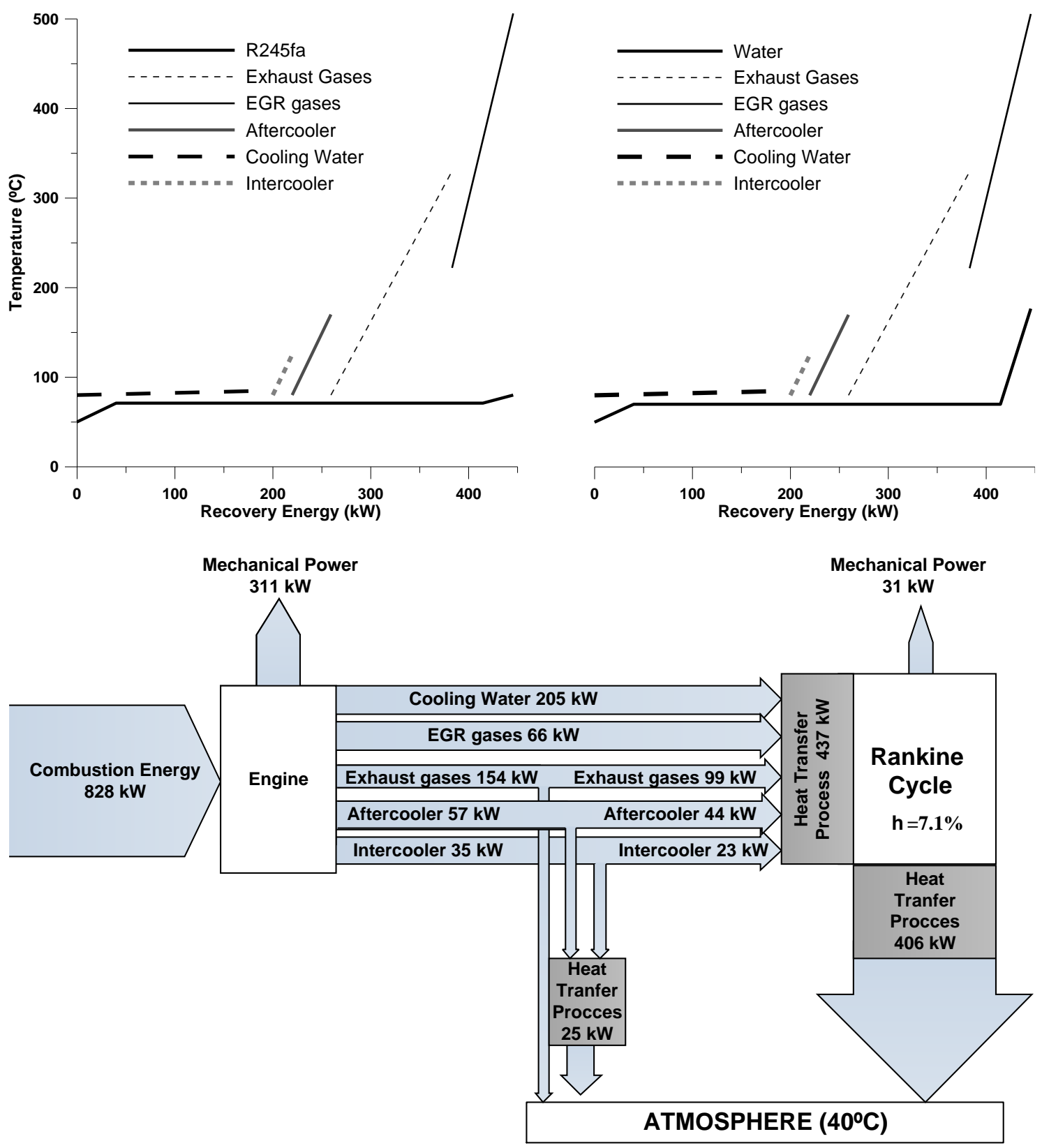

Figure 5. (Top) Temperature heat sources vs transferred heat in a single cycle with all the waste heat sources. (Bottom) energy scheme with the highest power output configuration.

Figure 5 shows that the Rankine cycle has a significant effect on total power compared with the Reference engine system ( $311 \mathrm{~kW}$ of the engine plus $31 \mathrm{~kW}$ provided by the cycle). This increment is equivalent to a $10 \%$ of power increment over the reference configuration. One of the biggest drawbacks of this configuration would be the important increase in the total heat transfer processes ( $868 \mathrm{~kW}$ vs 357 $\mathrm{kW}$ in the reference engine configuration) and consequently in the size of the heat exchangers.

\section{Configuration with all heat sources. Binary Cycle}

In the previous section, R245fa and water have been initially selected as the best solution for low and high evaporation temperatures respectively. For this reason, the use of two coupled cycles (binary cycle) tries to obtain the maximum power from all the considered heat sources. The iterative-parametric study is 
performed in order to accomplish these criteria. The fluid tables are used in order to obtain the optimal combination of: maximum temperature cycle, evaporation and condensation temperature and mass flow.

Steam Cycle Output Power (kW)

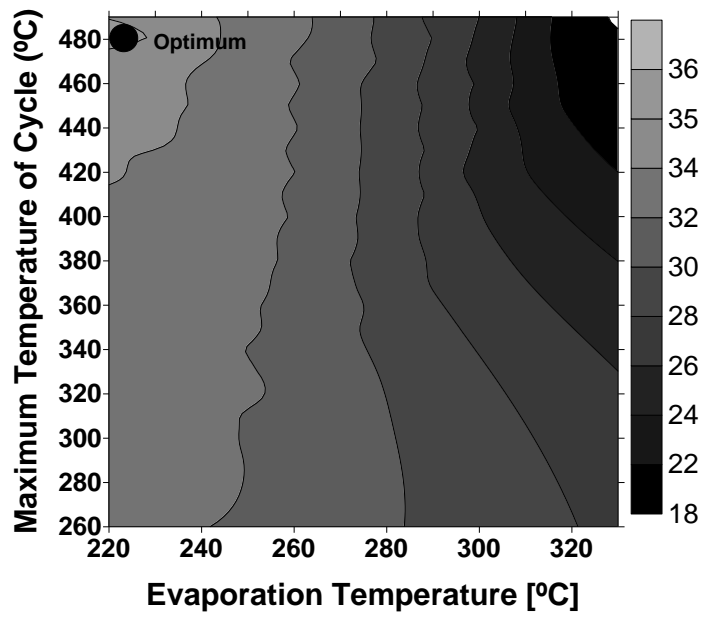

Working Fluid mass flow $(\mathrm{kg} / \mathrm{s})$

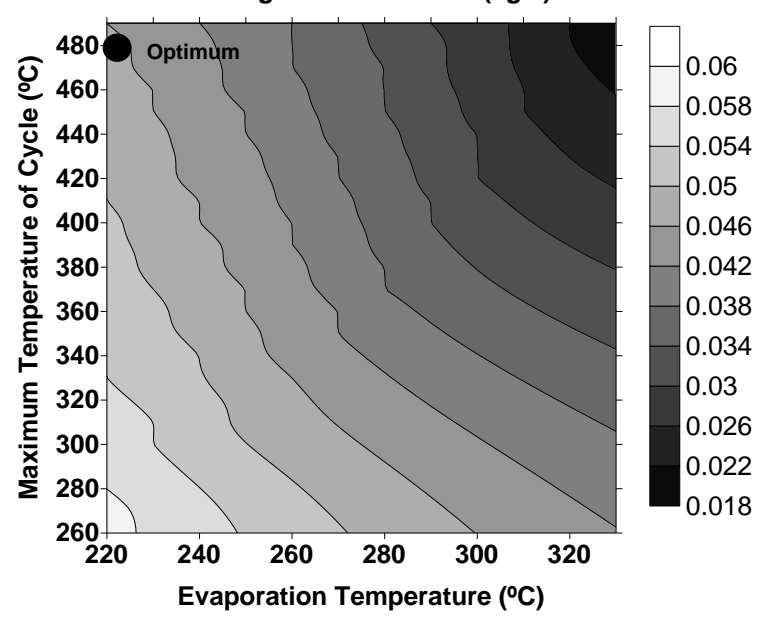

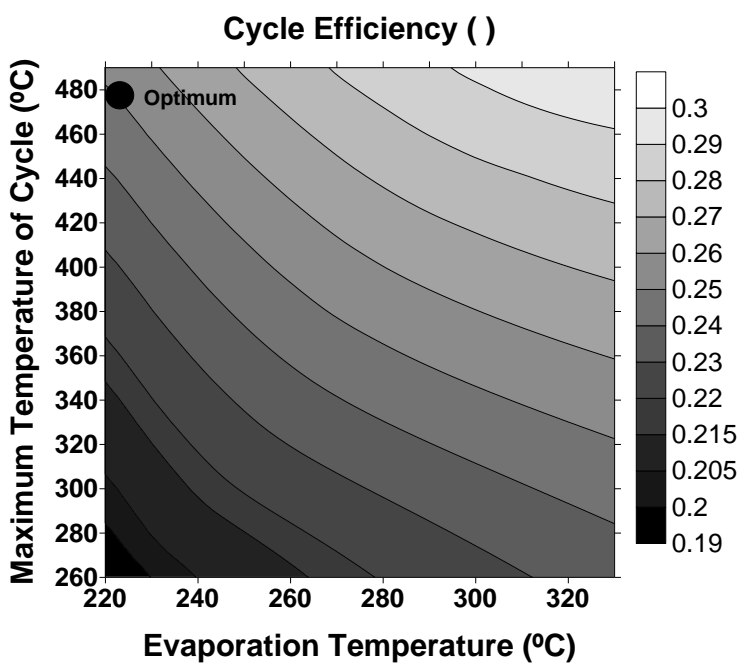

Figure 6. 2-D plot of Output Power, Working Fluid mass flow and Cycle Efficiency varying evaporator and maximum cycle temperature (condensation temperature $100^{\circ} \mathrm{C}$ ).

Figure 6 shows the results for the studied water cycles considering the maximum temperature and the evaporation temperature of the cycle as the independent variables. The condensation conditions have been fixed to $100^{\circ} \mathrm{C}$ and 1 bar due to technological reasons.

The optimal solution needs an agreement between maximum temperature and the working fluid mass flow to obtain the greatest power output. The top left graph in Figure 7 represents the different heat transfer processes taking place in the high temperature cycle (Water cycle). Heat sources are represented by the thin lines. The black bold line represents the working fluid evaporation process. The graph shows that the water is heated from $137^{\circ} \mathrm{C}$ to $220^{\circ} \mathrm{C}$ by the exhaust gas heat source. At this point, the water evaporates at constant pressure receiving heat from the exhaust gases and the EGR cooler. The rest of the EGR cooler heat is used for heating the steam up to $470^{\circ} \mathrm{C}$. The superheated steam will then be expanded through the turbine. 
The working fluid used in the low temperature cycle must be an organic fluid. In the previous section, the R245fa has been selected as the best option for this kind of cycles and it is used in this case. In this cycle, the heat absorbed by the R245fa in the beginning of the evaporation process is the heat released by the non-recirculated exhaust gases energy, the high temperature cycle condenser, intercooler, cooling water and the aftercooler, as shown in bottom graph in Figure 7. In this case, the heat sources have temperatures between $195^{\circ} \mathrm{C}$ and $80^{\circ} \mathrm{C}$. The evaporation temperature must be lower than the temperature of cooling water to allow heat transfer between this heat source and the working fluid cycle. Thus, as shown in Figure 7, evaporation temperature is fixed in $71^{\circ} \mathrm{C}$ in the $\mathrm{R} 245 \mathrm{fa}$ cycle and this fluid enters in the expansion machine from saturated steam conditions. The heat transfer of each source is represented in the temperature vs transferred heat diagram in the top right side of Figure 7, showing the critical point (pinchpoint) in the low temperature vaporizer (PP2). The design criteria used at PP2 is the same that was used at PP1. The condensation temperature in the low temperature cycle is fixed at $50^{\circ} \mathrm{C}$ to ensure the cooling of the condenser with the atmosphere at $40{ }^{\circ} \mathrm{C}$.
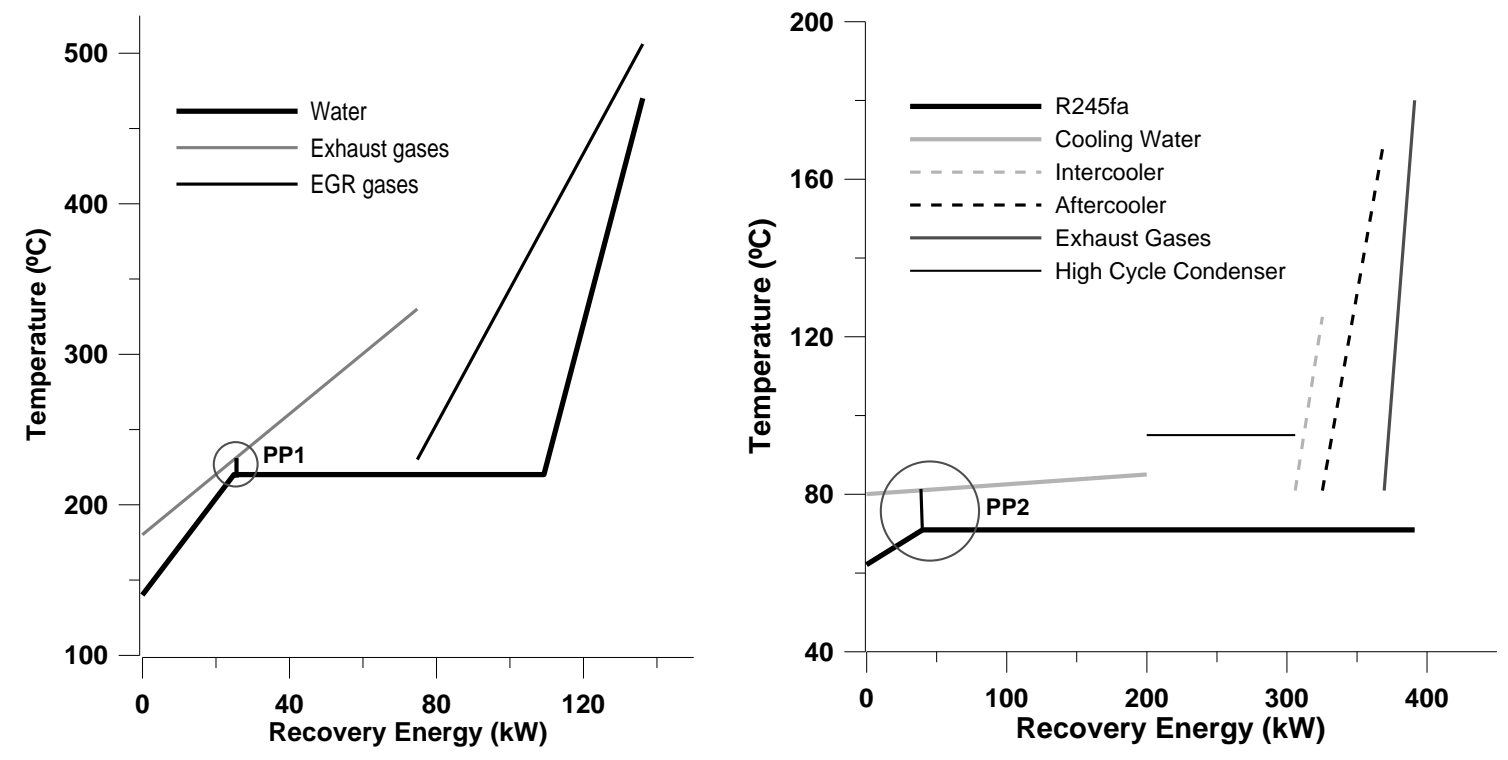


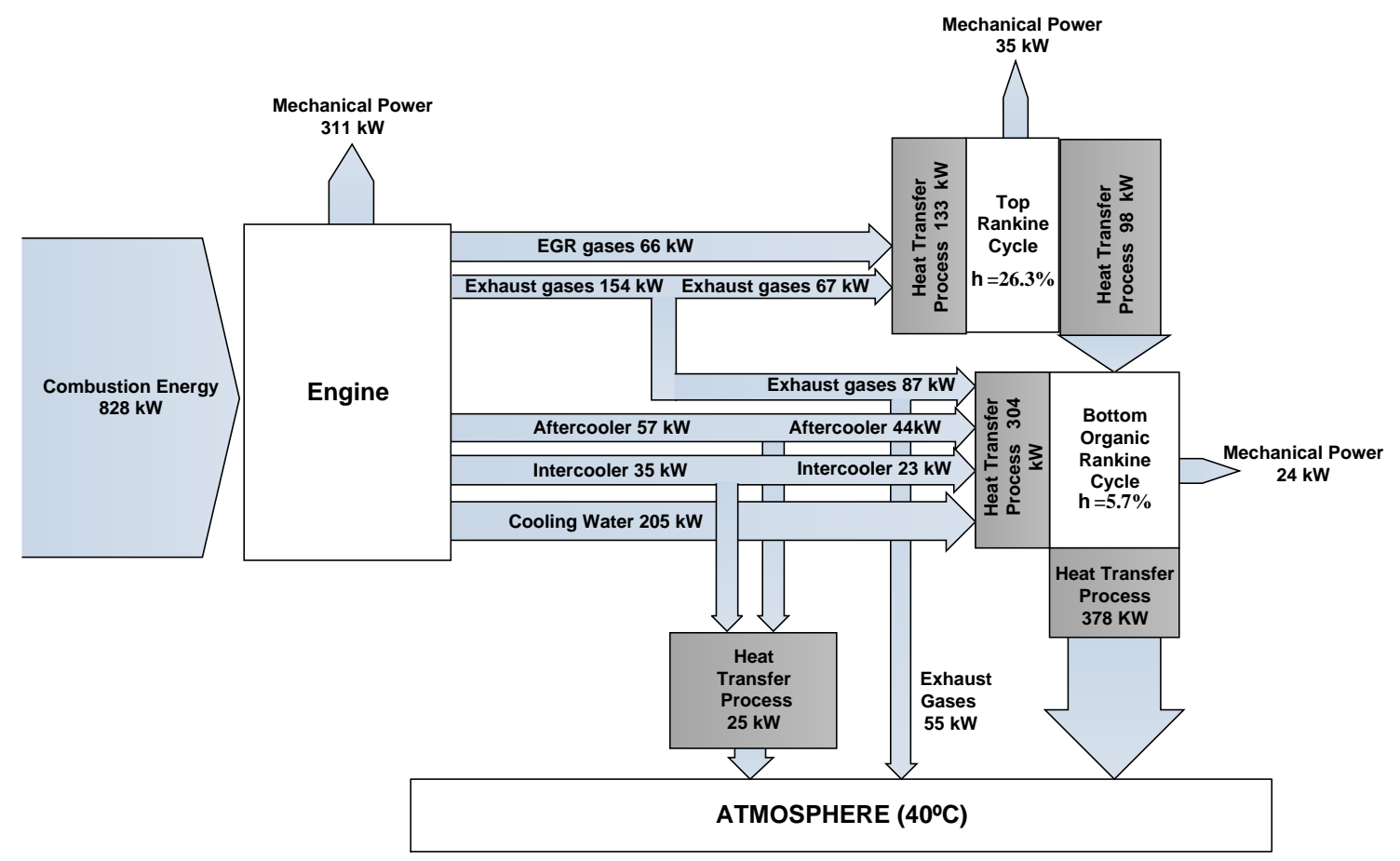

Figure 7. (Top) Temperature heat sources vs transferred heat in Top and Bottom cycle. (Bottom) energy scheme of binary cycle configuration.

The binary cycle has a significant effect on the total power compared to the Reference engine system. The binary cycle produces a mechanical power of $59 \mathrm{~kW}$ ( $35 \mathrm{~kW}$ in the Top Rankine Cycle plus $24 \mathrm{~kW}$ in the Bottom Organic Rankine Cycle). Clearly, $59 \mathrm{~kW}$, which is about $19 \%$ of effective power, can be stated as an ideal figure since only external irreversibilities have been considered during binary cycle analysis. In addition, as in the previous configuration, one of the problems is an important increase of the dissipated heat in the heat-exchangers, since the heat transferred was increased to almost $170 \%$ by the two thermodynamic cycles. (938 kW in binary cycle configuration versus $357 \mathrm{~kW}$ in the reference configuration).

\section{Configuration with high temperature heat sources}

In the previous solutions, many heat sources with different temperature ranges have been considered. That solution provided a considerable increase in total engine efficiency, but it must deal with important technical difficulties due to the heat control system of all the heat transfer processes and the low temperature of some sources. Consequently, a configuration with only high temperature heat sources, therefore using less heat sources, has been also investigated in order to obtain a more realistic technical solution. The EGR cooler, exhaust gases and Aftercooler are the best suitable sources for recovering heat taking into account their high temperatures. Different working fluids and different cycles have been studied using the maximum output power as a goal. The result of these studies gives a water Rankine cycle as the best option, since it is possible to reach a superheat temperature of $500^{\circ} \mathrm{C}$. 
The same iterative-parametric study, done previously, has been carried out in this case, with the same objective as for the configuration with all heat sources. Figure 8 shows the main variables of this parametric study. The water cycle has been optimized and this cycle has a $143^{\circ} \mathrm{C}$ vaporization temperature, a superheating temperature up to $485^{\circ} \mathrm{C}$ and regeneration. The condensation temperature is $50^{\circ} \mathrm{C}$ due to the heat transfer and the pinch-point criteria. The right striped area indicates the Rankine cycles in which the expansion ratio is higher than 25.
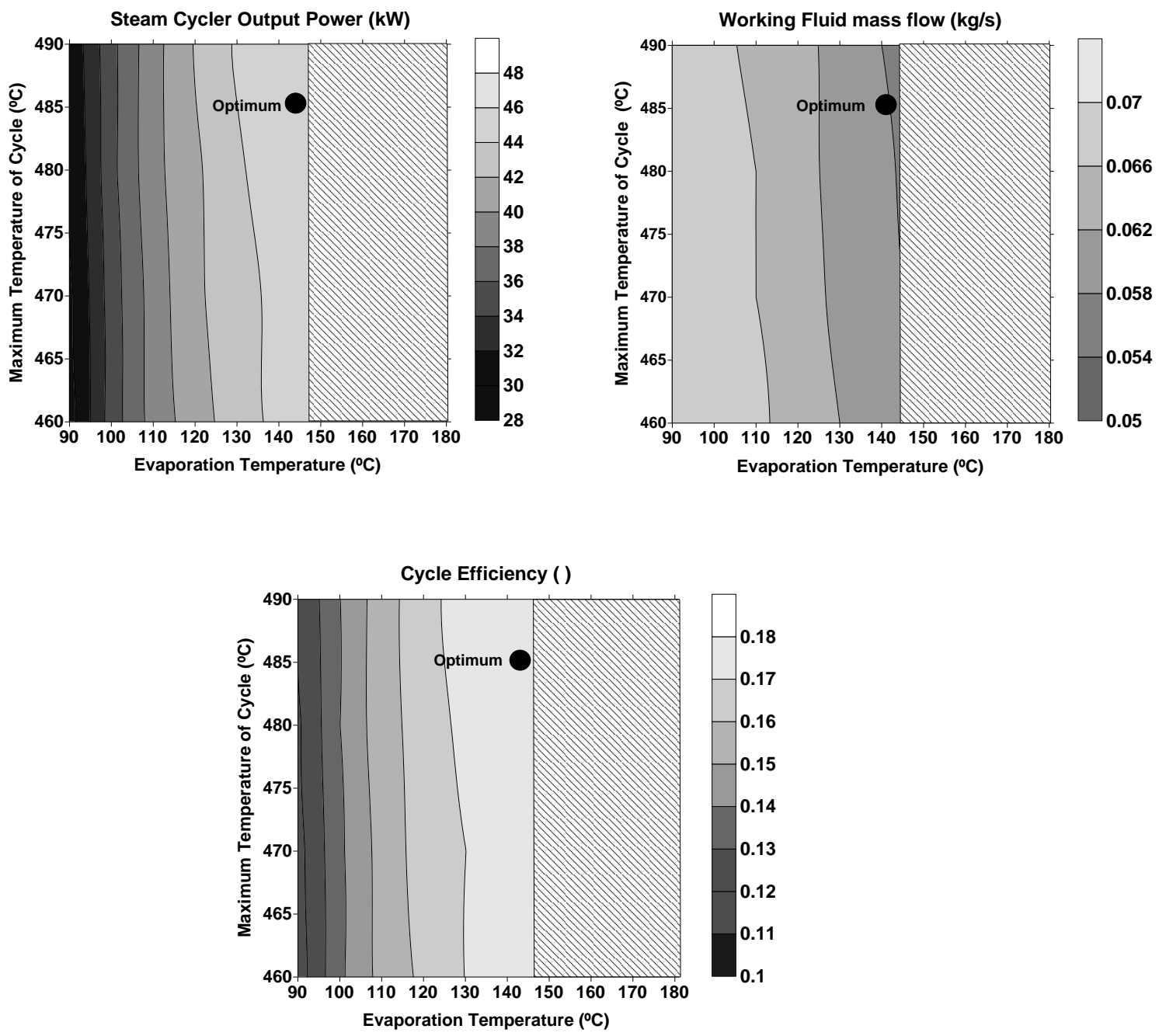

Figure 8. 2-D plot of Output Power, Working Fluid mass flow and Cycle Efficiency varying evaporator and maximum cycle temperature (condensation temperature $50^{\circ} \mathrm{C}$ ). 

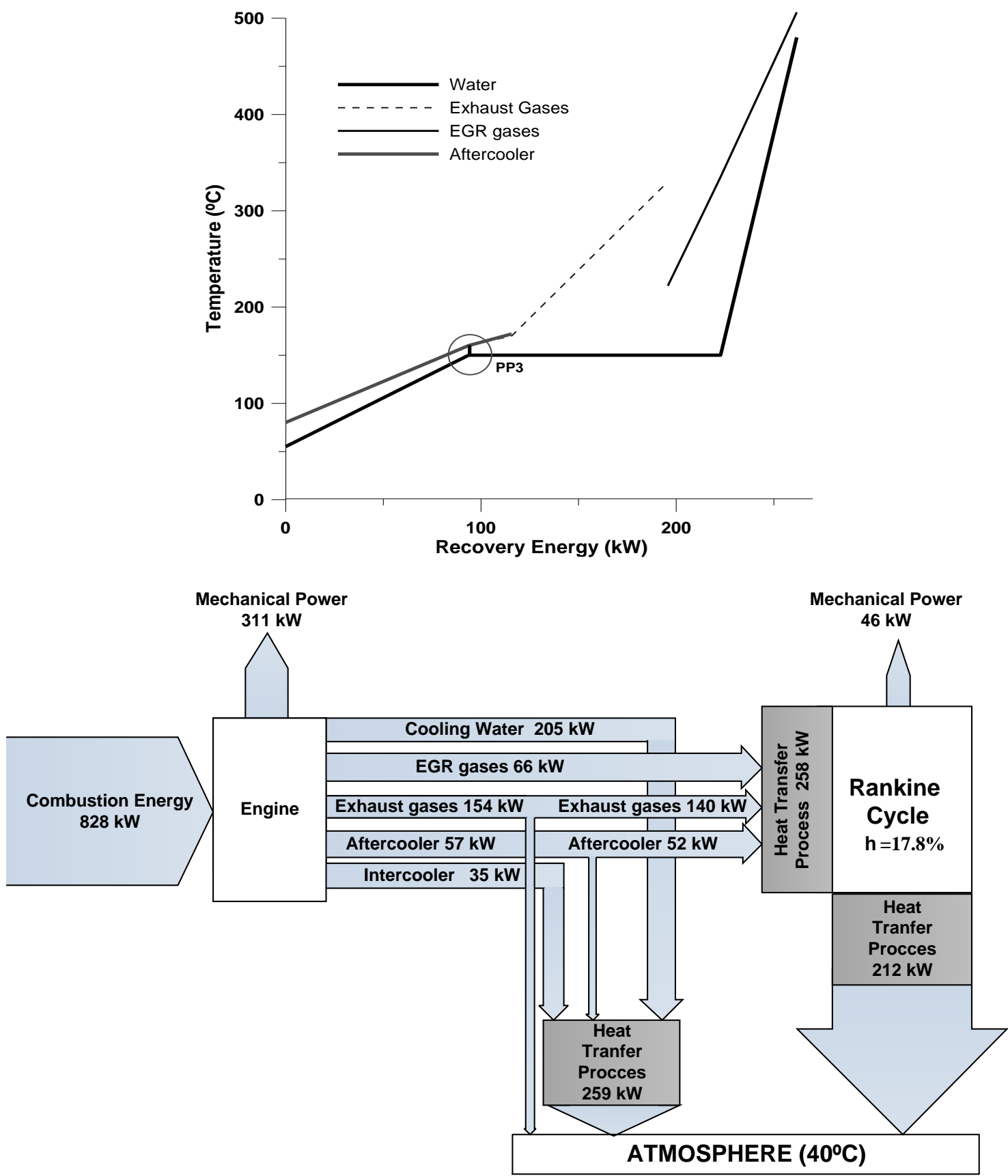

Figure 9. (Top) Temperature heat sources vs transferred heat in the configuration with high temperature heat sources. (Bottom) energy scheme cycle configuration.

The top graph in Figure 9 shows the evaporation process between the working fluid and the three heat sources. This figure confirms how the critical point is again the pinch-point (PP3). Figure 9 (bottom graph) shows all the high temperature heat sources used in the Rankine cycle. Only a small part of the power of exhaust gases and aftercooler can not be used in the cycle, due to their low temperatures.

This configuration with high temperature heat sources produces an increase in the output power about 46 $\mathrm{kW}$ (as can seen in the bottom graph in Figure 9) instead of the $59 \mathrm{~kW}$ that was achieved using the configuration with all heat sources. Although the heat dissipated in the configuration with high temperature heat sources is lower than in the configuration with all heat sources, this still needs a heat 
exchange larger than the exchanger used in the reference engine. However, it would allow the installation of the configuration with high temperature heat sources in an HDD engine since space requirements are not so large.

\section{Summary}

Table 4 summarizes the main results obtained in the configurations described in this paper. As show the table, the high power increment is produced by the configuration with all the heat sources with a binary cycle. But the important increase in total heat transfer could be a problem to design the necessary heat exchangers. Thus, the best solution with lower heat transfer rates is the configuration with only the high temperature heat sources.

Table 4. Summary results

\begin{tabular}{|c|c|c|c|c|}
\hline \multirow[t]{2}{*}{ Configurations } & & & & \\
\hline & $\begin{array}{l}\text { Output } \\
\text { power } \\
(\mathrm{kW})\end{array}$ & $\begin{array}{c}\text { Power } \\
\text { Increment } \\
(\%) \\
\end{array}$ & $\begin{array}{c}\text { Total Heat Transfer } \\
\text { Process } \\
(\mathrm{kW}) \\
\end{array}$ & $\begin{array}{c}\text { bsfc } \\
\text { reduction } \\
(\%)\end{array}$ \\
\hline Reference configurations & 311 & - & 357 & - \\
\hline $\begin{array}{l}\text { C. all heat sources: } \\
\text { Water Rankine Cycle }\end{array}$ & 342 & $10.0 \%$ & 868 & $8.8 \%$ \\
\hline $\begin{array}{l}\text { C. all heat sources: } \\
\text { Binary cycle }\end{array}$ & 370 & $19.0 \%$ & 938 & $16.0 \%$ \\
\hline $\begin{array}{l}\text { C. high temp. heat sources: } \\
\text { Water Rankine cycle }\end{array}$ & 357 & $14.7 \%$ & 729 & $8.5 \%$ \\
\hline
\end{tabular}

\section{Conclusions}

A method to analyze different possibilities to use waste energies in a Diesel engine is described in the present paper. This method involves estimating wasted energy values and uses this information to analyze the application of these energy sources in a bottoming Rankine cycle. Mechanical energy of a Diesel engine is about half of the total wasted energy. An important part of this wasted energy is used as thermal energy in intercoolers, radiators and exhaust gases expelled to the atmosphere. However, an important problem to recover these wasted thermal energies is the low temperature values of the available sources. Thus, it is difficult to achieve an acceptable efficiency using these sources.

The configuration with all heat sources includes waste energy recovery in two different cycles (binary cycle). The main problem of this solution is the big size of heat exchanger surface necessary.

The configuration with high temperature heat sources uses only high temperature waste energy sources in a water Rankine cycle. This solution is more realistic, but reduces the energy recovery in comparison with the configuration with all heat sources.

The external irreversibilities of this Rankine cycle have been extensively studied in the present work. The most important conclusion in the studied cases, with ideal processes and when the engine dissipates more heat energy is that it can only recover between $8 \%$ and $9 \%$ of the total energy dissipated by the engine once internal irreverisibilities are also considered. Thus, because the characteristics of the residual heat in 
the studied engine operating point (maximum speed and maximum load), the resulting optimal working fluid is water. However, this type of engine, working in partial loads, have different operating conditions, meaning that the organic fluids (ORC) are more optimal for energy recovery. Therefore, the working fluid used will depend on engine operating conditions where the energy of these residual sources will be recovered. This paper is a study of maximum and these problems have not been addressed, leaving them for a future work.

\section{Acknowledgements}

This work was partially funded by "Programa de Apoyo a la Investigación y Desarrollo de la Universidad Politécnica de Valencia" and "Programa de Formación de Profesorado Universitario".

\section{References}

[1]. Hountalas DT, Katsanos CO,Kouremenos DA, Rogdakis ED. Study of available exhaust gas heat recovery technologies for HD Diesel engine applications. International Journal of Alternative Propulsion (IJAP) 2007,1:228-49.

[2]. Brands MC. Werner J and Hoehne J L. Vehicle testing of Cummis turbocompound Diesel engine. In: SAE Paper $810073 ; 1981$.

[3]. Hopmann U. Diesel engine waste heat recovery utilizing electric turbocompound technology. In Annual diesel engine emissions reduction (DEER) conference, San Diego, (California).2004.

[4]. Weerasinghea WMSR, Stobarta RK and Hounshama SM. Thermal Efficiency Improvement in High Output Diesel Engines A Comparison of a Rankine Cycle with Turbo-compounding. Applied Thermal Energy (ATE) 2010:30:2253-56.

[5]. Bass JC, Kushch AS and Elsner NB. Thermoelectric generator (TEG) on heavy Diesel Trucks.In HiZ Technology Inc. Piscataway, NJ (USA).2001

[6]. Kushch AS, Bass JC, Ghamaty S and Elsner N B. Thermoelectric development at Hi-Z Technology. In Annual diesel engine emissions reduction (DEER) conference, San diego, (California) 2002.

[7]. Chacartegui R, Sánchez D, Muñoz JM and Sánchez T. Alternative ORC bottoming cycles for combined cycle power plants. Applied Energy 2009;86:2162-70.

[8]. Aly SE. Diesel engine waste-heat power cycle. Applied Energy 1988;29:179-189.

[9]. Bailey MM. Comparative evaluation of three alternative power cycles for waste heat recovery form the exhaust of adiabatic Diesel engines. National Aeronautics and Space Administration, 1985, (Washington, DC)

[10]. Doyle E, Dinanno L and Kramer S. Installation of a Diesel Organic-Rankine Compound engine in a class 8 truck for a single-vehicle test. In: SAE Paper 790646;1985.

[11]. Endo T, Kawajiri S, Kojima Y, Takahashi K, Baba T, Ibaraki S, Takahashi T and Shinohara M. Study on Maximizing Exergy . In: SAE Paper 2007-01-0257;2007. 
[12]. Serrano J R, Arnau F J, Dolz V, Tiseira A, Lejeune M and Auffret N. Analysis of the capabilities of a two-stage turbocharging system to fulfil the US2007 anti-pollution directive for heavy duty Diesel engines. International Journal of Automotive Technology 2008; 9:3:277-288.

[13]. On the Web: http://www.cmt.upv.es/OpenWAM.aspx

[14]. Galindo J, Serrano J R, Arnau J R and Piqueras P. Description and analysis of a one-dimensional gas-dynamics model with independent time discretization. ASME Internal Combustion Engine Division 2008;131:3:034504 (5 pages)

[15]. Payri F, Galindo J, Serrano JR and Arnau FJ. Analysis of numerical methods to solve onedimensional fluid-dynamics governing equations under impulsive flow in tapered ducts. International Journal Mechanical Sciences 2004;40: 981-1004.

[16]. Galindo, J, Luján, JM., Serrano, JR. snd Hernández, L. Combustion simulation of turbocharger HSDI Diesel engines during transient operation using neural networks Applied Thermal Engineering (ATE), 2005;25:877-98.

[17]. Serrano, J.R., Climent, H., Guardiola, C., Piqueras, P. Methodology for characterisation and simulation of turbocharged Diesel engines combustion during transient operation. Part 2: Phenomenological combustion simulation. Applied Thermal Engineering (ATE) 2009; 29:150-58.

[18]. Reyes M. Heat Transfer model for exhaust manifolds in reciprocating engines. PhD Thesis, (text in Spanish) Universidad Politécnica de Valencia 1994.

[19].Santos R. Study of the exhaust gas energy uses in Diesel engines. PhD Thesis (text in Spanish), Universidad Politécnica de Valencia 1999.

[20]. Galindo J, Luján JM, Serrano JR, Dolz V and Guilain S. Description of a heat transfer model suitable to calculate transient processes of turbocharged Diesel engine with one-dimensional gas-dynamic codes. Applied Thermal Engineering (ATE) 2006; 29:66-76.

[21]. Serrano, J.R., Arnau, F.J., Dolz, V., Tiseira, A., Cervelló, C. A model of turbocharger radial turbines appropriate to be used in zero- and one-dimensional gas dynamics codes for internal combustion engines modelling. Energy Conversion and Management 2008; 49:3729-45.

[22]. Galindo, J., Serrano, J.R., Climent, H., Tiseira, A. Experiments and modelling of surge in small centrifugal compressor for automotive engines. Experimental Thermal and Fluid Science 2008; 32: 81826.

[23].Benajes J, Bermúdez, V, and Galindo, J. Efecto de la geometría del intercooler en las prestaciones de motores de automoción. XI Congreso Nacional de Ingeniería Mecánica 1994.

[24]. Payri, F., Benajes, J., and Galindo, J.,. One-dimensional fluid-dynamic model for catalytic converters in automotive engines..In: SAE Paper 959785;1995.

[25]. Somayaji C, Mago P and Chamra LM. Second law analysis and optimization of Organic Rankine Cycles. ASME Power conference ,Atlanta (Georgia).2006. 
[26]. M. Moran, H. Shapiro, Fundamentals of Engineering Thermodynamics, fifth ed., John Wiley, New York, 2003.

[27]. Mago P, Chamra L M, Srinivasan K, Somayaji C. An examination of regenerative organic Rankine cycles using dry fluids. Applied Thermal Engineering 2007;29:1207-17

[28]. Drescher U and Brüggermann D. Fluid selection for the Organic Rankine Cycle (ORC) in biomass power and heat plants. Applied Thermal Engineering 223-228.(2007)

[29]. Japikse, David and Baines NC. Introduction to Turbomachinery. Oxford University Press, 1994.

[30].On the web: www.barber-nichols.com/pdf/nsds_turbine_chart.pd

[31]. Angelino G, Clonna P di Paliano. Organic Rankine Cycles (ORCs) for energy recovery from molten carbonate fuel cells. Intersociety Energy Conversion Engineering Conference and Exhibit (IECEC), Las Vegas (USA) 2000.

[32]. On the web: www.honeywellrefrigerants.com. 